\title{
スポーツ教育学研究 正誤表
}

P. 28 L. 7

To practice a sport is not what physical education aims at. In order for sporting materials to serve for Physical education. it is on all accounts necessary that they should be adjustat. to. and digested by. their learners Only if so. sports can be their blood and nesh.

In this light. I think we must reconsider sporting matertals in terms of physical education.

This time I have examined this problem. concentrating on the whole domain of apparatus gymnastics. M) conclusion is that the kind of apparatus exercises in the regular curriculum. whether the horizontal bar exercises. which we should aim to teach our students or pupils must never be exhibition skills such as excellent representative players do. They are indifferent and sometimes even harmful to the students.

Analyzing materials for apparatus symnastios from the above menuoned view-point and having it in my mind that there should be no student who cannot master the skills aimed at. I have originated a new system of instruction which is really available to any student and any teacher. Thus we have established apparatus exercises as being significant as materials for physical education or as materials for teaching sports. not merely as skills for competition.

I think that what I have said above is what is now to be earnestly searched after in all sporting materials.

\section{上記の部分が P. 35に移り、以下のようになります。}

\section{Basal Study of Review of Teaching Materials from the Standpoint of "Sports Pedagogy"}

\section{Yasuyuki ISHIDA Kanazawa University Abstract}

To practice a sport is not what physical education aims at. In order for sporting materials to serve for Physical education it is on all accounts necessary that they should be adjusted. to. and digested by. their learners. Only if so. sports can be their blood and nesh.

In this light. I think we must reconsider sporting materials in terms of physical education.

This time I have examined this problem, concentrating on the whole domain of apparatus gymnastics. My conclusion is that the kind of apparatus exercises in the regular curriculum. whether the horizontal bar exercises. which we should aim to teach our students or pupils must never be exhibition skills such as excellent representative players do. They are indifferent and sometimes even harmful to the students.

Analyzing materials for apparatus gymnastic from the above mentioned view-point and having it in my mind that there should be no student who cannot master the skills aimed at, 1 have originated a new system of instruction which is really available to any student and any teacher. Thus we have established apparatus exercises as being significant as materials for physical education or as materials for teaching sports. not merely as skills for competition.

I think that what I have said above is what is now to be earnestly searched after in all sportine materials. 